\title{
A comprehensive educational programme was effective for inner city patients with asthma
}

George MR, O'Dowd LC, Martin I, et al. A comprehensive educational program improves clinical outcome measures in inner-city patients with asthma. Arch Intern Med 1999 Aug 9/23;159:1710-6.

QUESTION: Does a comprehensive educational programme improve outpatient follow up and decrease subsequent hospital admissions in inner city patients with acute asthma?

\section{Design}

Randomised (allocation concealed), unblinded, controlled trial with 6 months of follow up.

\section{Setting}

A university hospital in Philadelphia, Pennsylvania, USA.

\section{Patients}

77 patients between 18 and 45 years of age (mean age $29 \mathrm{y}, 79 \%$ women) who were admitted from the emergency department (ED) with acute asthma and who lived in the inner city. Exclusion criteria were comorbid disease, inability to speak English, lack of telephone access, or pregnancy. Follow up was 100\%.

\section{Intervention}

44 patients were allocated to an educational programme including inpatient asthma education by an asthma nurse specialist, bedside spirometry, discharge planning assistance, a telephone call 24 hours after discharge, and scheduled outpatient follow up within 1 week of discharge (intervention group). 33 patients were allocated to conventional asthma care and routine follow up (routine care group).

\section{Main outcome measures}

Length of hospital stay, success of discharge (defined as not requiring emergency care in the 1 wk after discharge), attendance at follow up appointments, subsequent ED visits, and hospitalisations.

Sources of funding: National Institutes of Health; Health Management

Alternatives; Abbott

Laboratories; Mary

Rockefeller Foundation;

Merck Eे Co;

Schering-Plough/Key

Pharmaceuticals.

For correspondence:

Dr R A Panettieri jr,

Pulmonary and Critical

Care Division, BRB

II/III, University of

Pennsylvania Medical

Center, 421 Civic

Boulevard, Philadelphia,

PA 19104-6160, USA.

Fax +12155734469 .

\section{Main results}

No difference existed between intervention and routine care groups for mean length of hospital stay $(2.1 v 2.7 \mathrm{~d}$, $\mathrm{p}=0.12)$ or the rate of success of discharge $(100 \% v$ $97 \%)(\mathrm{p}=0.2) *$. Compared with patients in the routine care group, those in the intervention group had a higher rate of outpatient follow up $(\mathrm{p}=0.01)$ (table), fewer subsequent ED visits ( $3 \approx 15, \mathrm{p}=0.04)$, and fewer hospitalisations for asthma $(3 v 12, \mathrm{p}=0.04)$.

\section{Conclusion}

A comprehensive educational programme improved outpatient follow up and reduced subsequent emergency department visits and hospitalisations for inner city patients with asthma.

*p value calculated from data in paper.

Comprehensive educational programme v routine care for patients with asthmat

\begin{tabular}{lllll}
$\begin{array}{l}\text { Outcome at } \\
\mathbf{6} \text { mo }\end{array}$ & Intervention & Routine Care & $\begin{array}{l}\text { RBI } \\
(\mathbf{9 5 \%} \mathbf{C l})\end{array}$ & NNT (CI) \\
\hline Outpatient follow up & $59 \%$ & $27 \%$ & $\begin{array}{l}117 \% \\
(23 \text { to } 308)\end{array}$ & $\begin{array}{l}3 \\
\text { (2 to } 11)\end{array}$ \\
\hline
\end{tabular}

†Abbreviations defined in glossary; RBI, NNT, and $\mathrm{Cl}$ calculated from data in article.

\section{COMMENTARY}

This study by George $e t a l$, along with results of previous studies and the recommendations of published asthma practice guidelines, supports the notion that asthma education is an essential component of optimal asthma control. ${ }^{1-3}$ Recent studies have focused on outpatient asthma education programmes; this study makes a unique contribution by evaluating an asthma education programme initiated in hospital.

Overall, the study is well designed. It is a randomised controlled trial that compares a comprehensive asthma education programme with the provision of limited asthma information. The study had an adequate sample size to detect clinically meaningful differences in numbers of ED visits and hospitalisations; however, because no power calculation was provided, we do not know if the sample size was large enough to detect differences in the other outcomes. The study would have been stronger if it had included a cost analysis. The study was done in a university based hospital in a large US inner city and findings may be generalisable only to asthma patients in similar settings.

For nurses who work with similar asthma patients, this study shows the effectiveness of a comprehensive programme that includes sessions with an asthma clinical nurse specialist during the hospital stay. The purpose of these sessions was to improve metered dose inhaler administration technique; to stress the chronic nature of asthma and the need for long term treatment; to emphasise the importance of regular outpatient follow up; to teach the early warning signs of asthma and action plans for responding to these symptoms; to identify obstacles to care, such as inability to fill prescriptions and lack of transportation to outpatient appointments; and to work with the social worker to remove these obstacles. The programme also included telephone contact 24 hours after discharge to address questions about discharge instructions, medications, and asthma symptoms; outpatient follow up within 7 days after discharge for a repeat spirometric evaluation of forced vital capacity and forced expiratory volume; a physician examination; and reinforcement by the asthma nurse educator of principles learned during hospitalisation.

Lisa Cicutto, RN, ACNP, PhD Assistant Professor, University of Toronto Acute Care Nurse Practitioner, Respirology University Health Network Toronto, Ontario, Canada

1 Devine EC. Meta-analysis of the effects of psychoeducational care in adults with asthma. Res Nurs Health 1996;19:367-76.

2 Boulet L-P, Becker A, Bérubé D, et al for the Canadian Asthma Consensus Group. Canadian asthma consensus report, 1999. CMAJ 1999;161 (Suppl II): S1-5.

3 National Asthma Education and Prevention Program. Guidelines for the diagnosis and management of asthma: expert panel report. Bethesda MD: US Department of Health and Human Services, 1997. 